\title{
Bilateral Superior Accessory Renal Arteries - Its Embryological Basis and Surgical Importance - A Case Report
}

\section{G. Praveen Kumar*}

Department of Anatomy, Pinnamaneni Siddhartha Institute of Medical sciences \& research foundation, Chinoutpalli, Gannavaram, India

\begin{abstract}
During routine dissection of a male cadaver, in the Department of Anatomy, Pinnamaneni Siddhartha Institute of Medical science, presence of bilateral superior accessory renal arteries was noted. They took origin from the antero lateral aspect of abdominal aorta, below the origin of superior mesenteric artery and above the origin of main renal arteries. The main right and left renal arteries took their origin from the lateral aspect of abdominal aorta, at the level of the origin of inferior mesenteric artery. Proper knowledge of variations of the arteries supplying the kidney is essential not only to the anatomists but also to the vascular surgeons, urologists, nephrologists and radiologists. Such vascular variations as noted in the present study have been explained in light of embryogenic development.
\end{abstract}

Keywords: Renal artery; Abdominal aorta; Superior mesenteric artery; Inferior mesenteric artery; Accessory renal arteries

\section{Introduction}

Knowledge of the anatomy of the renal blood supply is important to every urologic surgeon, and fortunately this subject lends itself to easy investigation. Anatomists were keenly interested in renal vascular patterns before the end of the $19^{\text {th }}$ century, but the advent of aortography in the 1940s and 1950s spearheaded a systematic clinical approach to this topic.

Each kidney is normally supplied by a renal artery which is a branch of abdominal aorta. Right artery is longer than left one, because abdominal aorta lies on the left side of vertebral column [1].

Both right and left renal arteries branch laterally from the aorta just below the inferior mesenteric artery, and cross the corresponding crus of the diaphragm at right angles to the aorta. The right artery is often higher than the left one, passes posterior to the inferior vena cava, right renal vein, head of pancreas and descending part of duodenum. The left artery passes behind the left renal vein, the body of pancreas and splenic vein and may be crossed in front by the inferior mesenteric vein nearing the renal hilum. Specifically, the right renal artery leaves the aorta and progresses with a caudal slope under the inferior vena cava (IVC) toward the right kidney. The left renal artery courses almost directly laterally to the left kidney. Given the rotational axis of the kidney, both renal arteries move posteriorly as they enter the kidney. Also, both arteries have branches to the respective adrenal gland, renal pelvis, and ureter $[1,2]$

Anatomic variations in the renal vasculature are common, occurring in $25 \%$ to $40 \%$ of kidneys. The most common variation is presence of accessory renal arteries. One or two accessory renal arteries frequently occur, especially on the left, usually from the aorta above or below the main artery, the former slightly more often. They usually enter above or below the renal hilum. Lower pole arteries on either side can cross anterior to the collecting system, causing obstruction at the ureteropelvic junction [2]. On the right side, the lower pole arteries usually also cross anterior to the inferior vena cava [3].

Symptoms attributable to renal vascular anomalies are those that might result from inadequate urinary drainage. Accessory renal arteries may constrict an infundibulum, a major calyx, or the uretero-pelvic junction [4]. Pain, hematuria secondary to hydronephrosis, signs and symptoms of urinary tract infection, or calculus formation may result [2].

The accessory renal artery variations can be explained in the light of embryonic development from the lateral mesonephric branches of the dorsal aorta and its molecular regulation.

\section{Case Report}

During routine dissection of an old male cadaver, in the Department of Anatomy, Pinnamaneni Siddhartha Institute of Medical science, presence of bilateral superior accessory renal arteries was noted.

Accessory renal arteries were found to arise from the anterolateral sides of the abdominal aorta, between its two ventral branches superior and inferior mesenteric arteries; reaching the upper poles of both kidneys. The main renal arteries stemmed from the abdominal aorta at the level of origin of inferior mesenteric artery.

The right kidney, being supplied by two arteries (main renal artery and accessory renal artery), measured $12.6 \times 5 \times 2.8 \mathrm{~cm}$. The right superior accessory renal artery arose from abdominal aorta at the level of origin of superior mesenteric artery, while the right main renal artery from abdominal aorta $45 \mathrm{~mm}$ below the origin of superior mesenteric artery and just above the origin of inferior mesenteric artery. The caliber of right superior accessory renal artery was less, as compared to that of right main renal artery. The course of right superior accessory renal artery was oblique, reaching the upper pole of right kidney as compared to the straight course of right main renal artery reaching the right renal hilum anterior to the right ureter (Figure 1).

The left kidney, which was also supplied by two arteries (main

${ }^{*}$ Corresponding author: Dr. G. Praveen Kumar, Assistant professor, Department of Anatomy, Pinnamaneni Siddhartha Institute of Medical sciences\& research foundation, Chinoutpalli, Gannavaram, Andhra Pradesh -521286, Tel: $91-$ 9573274098; E-mail: praveengattu@yahoo.com

Received December 02, 2011; Accepted December 06, 2011; Published December 15, 2011

Citation: Praveen Kumar G (2012) Bilateral Superior Accessory Renal Arteries Its Embryological Basis and Surgical Importance - A Case Report. J Clinic Case Reports 2:e105. doi:10.4172/2165-7920.1000e105

Copyright: (c) 2012 Praveen Kumar G. This is an open-access article distributed under the terms of the Creative Commons Attribution License, which permits unrestricted use, distribution, and reproduction in any medium, provided the original author and source are credited. 


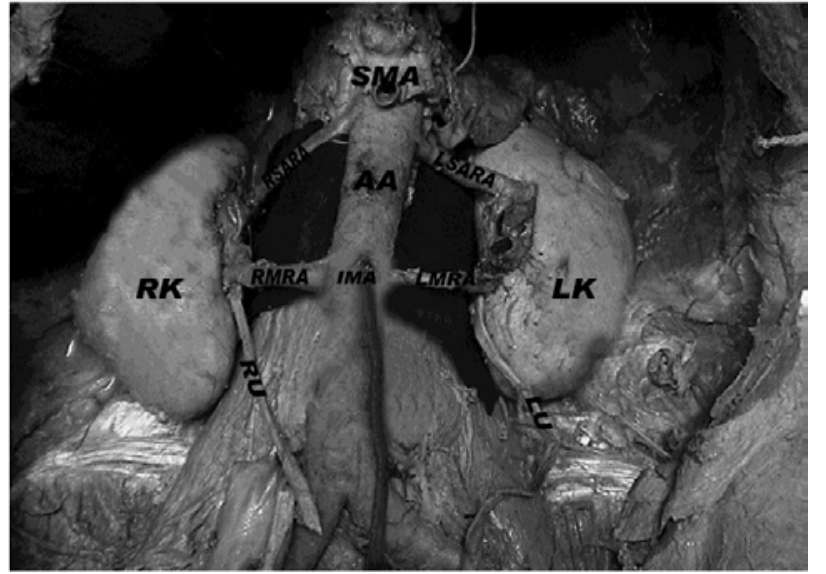

Figure 1: showing bilateral superior accessory renal arteries. (after removal of inferior venacava, right and left renal veins)

RK- Right kidney, LK- Left kidney, SMA-Superior mesenteric artery,

IMA-Inferior mesenteric artery, RSARA-Right superior accessory renal artery, LSARA-Left superior accessory renal artery, RMRA-Right main renal artery, LMRA-Left main renal artery, AA- Abdominal aorta, RU- Right ureter , LU-Left ureter.

and accessory renal arteries), measured $11.4 \times 5.8 \times 3.4 \mathrm{~cm}$. The left superior accessory renal artery arose from the abdominal aorta $4 \mathrm{~mm}$ below the origin of superior mesenteric artery. However, the left main renal artery emerged from abdominal aorta $46 \mathrm{~mm}$ below the origin of superior mesenteric artery and just above the origin of inferior mesenteric artery. The course of left superior accessory renal artery, destined for upper pole of left kidney, was straight and parallel to left main renal artery. The left main renal artery was passing anterior to the left ureter to reach the left renal hilum (Figure 1).

No other anomalies were observed in relation to the renal vasculature and morphology. The branching pattern of the abdominal aorta was otherwise normal.

\section{Discussion}

Traditional anatomy describes each kidney as receiving irrigation from a single renal artery. However, current literature reports great variability in renal blood supply, the number of renal arteries mentioned being the most frequently found variation. Such variation has great implications when surgery is indicated, such as in renal transplants, uroradiological procedures, renovascular hypertension, renal trauma and hydronephrosis.

Accessory renal arteries are common (30\% of individuals), and usually arise from the aorta above or below the main renal artery and follow it to the renal hilum. The lower renal segment is more frequently fed by an accessory vessel. Two or more renal arteries are more common on the left side. Accessory renal arteries are regarded as persistent embryonic lateral splanchnic arteries. Accessory vessels to the inferior pole cross anterior to the ureter and may, by obstructing the ureter, cause hydronephrosis. Rarely, accessory renal arteries arise from the coeliac or superior mesenteric arteries near the aortic bifurcation or from the common iliac arteries [1].

The main importance of the abnormality is as a source of potential error during operations in the retroperitoneum, especially those on the kidney. The renal arteries are functional end-arteries, so division of an aberrant lower pole artery leads to infarction of the section of renal parenchyma that it supplies [5].

Ozkan et al. [6] in his angiographic evaluation of origin and variation of renal arteries (163 females \& 692 males), found renal arteries originating between the first and second lumbar vertebral level in most patients. Variations of renal arteries included multiple arteries in $24 \%$, bilateral multiple arteries in $5 \%$, and early division in $8 \%$ of cases. Additional renal arteries on the right side were found in $16 \%$ and on the left side in $13 \%$ of cases. Bilateral aberrant renal arteries were found in $13-16 \%$ of cases. This result should be kept in mind when a non-invasive diagnostic search is performed for renal artery stenosis or when renal surgery related to renal arteries is performed [6].

Presence of bilateral accessory renal arteries can be explained in the light of embryogenic development and its molecular regulation. Each primitive dorsal aorta gives off ventral splanchnic arteries, lateral splanchnic arteries, somatic arteries and caudal continuation. The lateral splanchnic arteries supply, on each side, the mesonephros, metanephros, the testis or ovary and the suprarenal gland. All these structures develop, in whole or in part, from the intermediate mesenchyme of the mesonephric ridge. One testicular or ovarian artery and three suparenal arteries persist on each side. The phrenic artery branches from the most cranial suprarenal artery and the renal artery arises from the most caudal one. Additional renal arteries are frequently present and may be looked on as branches of persistent lateral splanchnic arteries [7].

Arey is of the view that anomalous blood vessels may be due to: a) choice of unusual paths in the primitive vascular plexuses; b) persistence of vessels normally obliterated; c) disappearance of vessels normally retained; d) incomplete development; and e) fusion and absorption of parts usually distinct [8].

After the induction of angioblasts (precursors to blood vessels), sonic hedgehog, secreted by the notochord, induces surrounding mesenchyme to express vascular endothelial growth factor (VEGF). In turn, VEGF expression induces the Notch pathway (a transmembrane receptor pathway), which specifies arterial development through expression of ephrinB2 (ephrins are ligands that bind to Eph receptors in a pathway involving tyrosine kinase signaling). Misexpression of one or more transcription factors as mentioned above may lead to aberration in the arterial development [9].

Knowledge and awareness of the possible variations and anomalies of the renal arteries including presence of accessory renal arteries are necessary for sufficient surgical management during renal transplantation, repair of abdominal aorta aneurysm, urological procedures and angiographic interventions. As the invasive interventions such as renal transplantation, interventional radiologic procedures and urologic operations increase, awareness of the possible variations of the renal arteries is necessary for adequate surgical management in the aforementioned specialties [10].

The nomenclature of renal arterial variations is still unclear. Nevertheless, it is a misnomer to call such vessels accessory, aberrant or even supernumerary because they are not extra but essential, tissue-sustaining arteries without anastomoses between them, which correspond to the segmental branches of a single renal artery [11]. 
Citation: Praveen Kumar G (2012) Bilateral Superior Accessory Renal Arteries - Its Embryological Basis and Surgical Importance - A Case Report. J Clinic Case Reports 2:e105. doi:10.4172/2165-7920.1000e105

\section{References}

1. Standring S, Ellis H, Healy JC (2005) Gray's Anatomy. In: Glass J (ed), Kidney and Ureter. $39^{\text {th }}$ edn. Churchill Livingstone Elsevier, London. 1274-1277.

2. Wein AJ, Kavoussi LR, Novick AC (2007) Campbell-Walsh Urology. In: Stuart B (ed), Anomalies of the Upper Urinary Tract. $9^{\text {th }}$ edn. Saunders Elsevier, Philadelphia. 263-266.

3. Williams PL, Bannister LK, Berry MM (1995) Gray's Anatomy. In: Gabella G(ed), Cardiovascular system.38th edn. Edinburgh, Churchill Livingstone. 1556-1557.

4. Yen TH, Chang CT, Huang CC, Ng KK, Tsai SY, et al. (2004) Bifurcated abdominal aorta, with a coarctation over the right branch of the bifurcated abdominal aorta and aberrant renal arteries originating from the left branch of the bifurcated abdominal aorta. Ren Fail 26: 83-87.

5. Williams NS, Bulstrode CJK, O'connell PR (2008) Bailey and Love's Short Practice of Surgery. In: Fowler C G (ed), The Kidneys and Ureters. $25^{\text {th }}$ edn. Edward Arnold, London. 1288.
6. Ozkan U, Oguzkurt L (2006) Renal artery origin and variations: Angiographic evaluation of 855 consecutive patients. Diagn Interv Radiol 1: 183-186.

7. Standring S, Ellis H, Healy JC, Johnson D, Williams A, et al. (2005) Gray's Anatomy.39th edn. Philadelphia Elsevier Churchill Livingstone 1274: 1042.

8. Arey LB (1957) Developmental Anatomy. In: Development of the arteries. 6th edn. WB Saunders Co, Philadelphia. 375-377.

9. Sadler TW (2010) Langman's Medical Embryology. In: Third to eighth weeks: The embryonic period. $11^{\text {th }}$ ed. Lippincott Williams \& Wilkins. Philadelphia, USA 81-82.

10. Patasi B, Boozary A (2009) A case report: accessory right renal artery International Journal of Anatomical Variations 2: 119-121.

11. Gurses AI, Kale A, Gayretli O, Bayraktar B, Usta A, et al. (2009) Bilatera variations of renal and testicular arteries. International Journal of Anatomical Variations 2: 45-47. 